\title{
5 Abjection in Play
}

\subsection{Performing Humanism}

In the previous chapter, I engaged with Viola Spolin's application of the term "intuition." Improv historiographer Janet Coleman considers Spolin's work "mystical and intuitive, attached to an energy that is asexual and childlike" (38). The idea of rediscovering your inner child through improv, of returning to one's self before culture, is a common concept in improv discourse. Improv is thought to help us discover ourselves as we really are, unhindered by social constraints, and the way to get there is through play or playing: an activity that infants and children are assumed to perform naturally, but one that for adults falls outside the real life of material demands. Playing requires intuitive actions and spontaneous decision-making. Among artists and audience alike, both are believed to lead towards higher authenticity, challenging the social norms that otherwise structure real life and social personas. In the final section of the previous chapter, I suggested that we define intuition as the reactive mode of play in the anti-Black libidinality that makes us, as adults, want to play in the first place and how this subject-making desire is always already anti-Black. In this chapter, I investigate the overlap or identity of the somatic states that make us feel like a coherent subject both in the general arena of play and when performing purposeful acts of anti-Black abjection, focusing on and how these mutually reinforce each other on the improv stage.

Play and playing feature significantly in anthropology and cultural studies, almost always in an idealized performance of Humanism. Schiller's everlasting statement in On the Aesthetic Education of Man - "Man plays only when he is in the full sense of the word a man, and he is only wholly Man when he is playing” (80) - is the first theory of play in the Western Humanist tradition. Later, anthropologist Victor Turner theorizes an allegedly universal and all-encompassing homo ludens-approach to playing and considers how subjects create culture when at play. Toward the end of the twentieth century, French sociologist Roger Caillois expands the concept of play to encompass social structures and many forms of behavior. He creates a new set of criteria for types and forms of play, such as the differentiation between "a primary power of improvisation and joy," which he terms "paidia," and a "taste for gratuitous difficulty" he terms "ludus." In many ways, improv mobilizes the concept of paidia, so named by Caillois because "it is the root of the word for child" (27). More, improvisers are called "players" more commonly than they are called "actors." The term "game" is used in the discourse in two different ways: Keith Johnstone and

Ә OpenAccess. (c) 2022 Michel Büch, published by De Gruyter. (cc) BY-NC-ND This work is licensed under the Creative Commons Attribution 4.0 International License. https://doi.org/10.1515/9783110752748-006 
Viola Spolin each developed "games" that prescribe rules for a scene. In certain US-based improv styles, the "game of the scene" is a dramaturgical term to describe the repetition of a pattern, for example a character's behavior. The collocation "free play" also features greatly, most commonly in titles for workshops or publications, such as Free Play: Power of Improvisation in Life and the Arts (Nachmanowitch). In addition, the play metaphor in improv connotes the egalitarian ideal of equality. By its nature, improv-as-play is believed to be inclusive and open for everyone:

Everyone can act. Everyone can improvise. Anyone who wishes to can play in the theater and learn to become "stageworthy." (Spolin 1)

Improvisational theater is the closest thing you'll find to democracy in the theater. It opens up the possibility of play between the people in the group, and play is an expression of our equality. The crowd I work with regard themselves as equals. (Paul Sills qtd. in Sweet 20)

Improvised play is assumed to provide a space in which everyone can be their truer, deeper, coherent, lively, and more creative self; more, in improv, we can be just like everyone else. The rules and opportunities are the same for everyone, because (according to this logic) in improv we perform our Humanity, and we're all Human. Or are we?

As much as the discourse seeks to present itself as beyond ideological constraints, its liberal racialized idealism plays out the same. In its romantic egalitarianism, improv discourse consistently ignores the fact that different social positions or non-positions rule out the possibility of fairness:

And why does it have to be that way where it is so segregated, and you need a white man, or you need a white woman, but you don't need more than just one black person's voice. Each of us have different voices. Each minority does. You can't have one minority represent all; that's unfair when you have three or four white guys up there. (Vaughn, personal conversation, emphasis mine)

People do think that everybody is equal. And in some ways they are right. We should be moving towards this era where it shouldn't matter what you look like or what you sound like or where you're from. It shouldn’t matter. But it still does. (Joel Boyd, personal conversation)

In an art form based on a romantically universalized but clearly white group mind, the idea of egalitarian play should not be thrown around so carelessly. While improv discourse and theory link theatrical improvisation with play, most of this theorizing a) accompanies self-description and idealized fictions of improv as a cultural phenomenon and, b) seeks to legitimize improv as worthy of academic consideration. My aim is not to reenact the circular or tautological arguments that human play defines humans because humans play. In fact, my 
discussion can be read against this assumption in that the desire to play as adults is based on the racialized dichotomy through which the modern subject describes itself qua anti-Black abjection. Using a psychoanalytic approach, I relate play in improv with embodied anti-Black abjection and self-making.

\subsection{Properties of play}

Caillois's concept of paidia "cover[s] the spontaneous manifestations of the play instinct” (28). He continues:

The elementary need for disturbance and tumult first appears as an impulse to touch, grasp, taste, smell and then drop any accessible object. It readily can become a taste for destruction and breaking things. It explains the pleasure in endlessly cutting up paper with a pair of scissors, pulling cloth into thread, breaking up a gathering [...] etc. Soon comes the desire to mystify or to defy by sticking out the tongue [...] For the child it is a question of expressing himself, of feeling he [sic] is the cause. (28)

What enables this "primitive joy in destruction" (28)? And how does it play out in adult play? First, we must recognize that an adult can never go back to their child emotions. The attempt to go back to an imagined child-state, to fancy oneself as transcendent of oneself (while being conscious of it), is a logical impossibility, an uncomfortably loud self-aggrandizement symptomatic of the power of lack in the descriptive statement of the modern Manichean subject.

Donald Winnicott has spent much of his academic and practical career working on children's play, its meanings, and its functions. In my reading, his models and theories link up closely with abjection as a raced, subject-making aeffect, particularly in connection with my previous discussion of Kristeva's abjection in its racialized contemporary realization. According to Winnicott, playing is essential to subject- or identity-formation, and for creativity and the creation of culture. Accordingly, I argue that play becomes a generative space for the adult subject-aeffect, by definition anti-Black. In Winnicott's theory, the original experience of playing takes place in a potential space between the mother-figure and the child. Resonating with Kristeva, the child forms itself in this space through unity with the mother and its repudiation. In this space, the child's body undergoes a sensation of bliss through unity with everything else as well as in having its first "not-me" experiences. The undecided oscillation between these (chemical, biopsychical) sensations makes up the potential space of play. Central to Winnicott's play theory is the concept of "transitional objects," through which the child links the realms of reality and fantasy. These objects function as the first possessions of a child and are "both created and discovered 
[yielding] freedom and joy to babies and all who were once babies" (Winnicott xi-xii). In this section, I briefly sketch out what this entails and link it to abjective jouissance qua dehumanizing, propertizing, anti-Black abjection. I then show how play - both for children and adults - involves aggression and can be related to fantasies of destruction as much as fantasies of self- and subjectmaking qua ownership claims. Not unexpectedly, we will see that these two poles of play are inextricably linked.

\section{The area of play}

Winnicott uses the terms "transitional object" or "transitional phenomena" to designate "the intermediate area of experience, between the thumb and the teddy bear, between the oral eroticism and the true object-relationship." Among these, he includes "an infant's babbling or the way an older child goes over a repertory of songs and tunes while preparing for sleep," and "the use made of objects that are not part of the infant's body yet are not fully recognized as belonging to an external reality." These he calls "first possessions," and they function as symbols by which the fantasy of maternal unity is recreated (2-3). He writes further:

\footnotetext{
It is true that the piece of blanket (or whatever it is) is symbolical of some part-object, such as the breast. Nevertheless, the point of it is not its symbolic value so much as its actuality. Its not being the breast (or the mother), although real, is as important as the fact that it stands for the breast (or the mother). (8)
}

Winnicott focuses on a space in which symbolism and actuality exist simultaneously; transitional objects allow "room for the process of becoming able to accept difference and similarity" (8). He clarifies the paradox that defines the transitional object, which must be accepted rather than resolved or decided:

\footnotetext{
The transitional object is not an internal object (which is a mental concept) - it is a possession. Yet it is not (for the infant) an external object either. [The] internal object depends for its qualities on the existence and aliveness and behavior of the external object. [...] The transitional object may therefore stand for the "external" breast, but indirectly, through standing for an "internal" breast. The transitional object is never under magical control like the internal object, nor is it outside control as the real mother is. (13)
}

To justify my consideration of Winnicott here, let me clarify a link I see to Kristeva. She too grounds abjection in the infant's experience of breastfeeding or its substitute, and though this is not Winnicott's focus, breastfeeding prefigures the 
visceral goings-on that develop later when the infant enters the potential space of play. To understand the physico-psychical grounding of play in Winnicott, we must keep in mind the way in which breastfeeding creates the first experience of physical bliss for the newborn. Ignorant of concepts like "hunger," infants learn generically that there is something that will lead to homeostasis, irrespective of where the tension lies. Winnicott writes:

[A]t some theoretical point early in the development of every human individual an infant in
a certain setting provided by the mother is capable of conceiving of the idea of something
that would meet the growing need that arises out of instinctual tension. [...] The infant can-
not be said to know at first what is to be created. At this point in time the mother presents
herself. [...] The mother's adaptation to the infant's needs, when good enough, gives the in-
fant the illusion that there is an external reality that corresponds to the infant's own capaci-
ty to create. [...] To the observer, the child perceives what the mother actually presents, but
this is not the whole truth. The infant perceives the breast only in so far as a breast could be
created just there and then. There is no interchange between the mother and the infant.
Psychologically the infant takes from the breast that is part of the infant, and the mother
gives milk to an infant that is part of herself. $(15-16)$

The transitional object, then, stands in for the breast in as much as it recreates the illusion that one can create or find an object that will "meet a growing need that arises out of instinctual tension" (16). Whether this object is created or found is irrelevant: "The important point is that no decision on this point is expected. The question is not to be formulated" (17). (Kristeva's concept of abjection specifies an adult subject's need for occasional, undecided transitionality. Broeck then provides us with a culturally specific cure for this blissful crisis.) To sum up:

\footnotetext{
The object is a symbol of the union of the baby and the mother (or part of the mother). This symbol can be located. It is at the place in space and time where and when the mother is in transition from being (in the baby's mind) merged in with the infant and alternatively being experienced as an object to be perceived rather than conceived of. The use of an object symbolizes the union of two now separate things, baby and mother, at the point in time and space of the initiation of their state of separateness. (Winnicott 130)
}

With Winnicott, we can perceive this "time and space" as the area and activity of play, in the simultaneity of internal and external experience realized through the transitional object and accompanied by all its fears and desires. Playing is a mode of exerting magical control on objects. It is not an inner, individual psychic self, nor is it entirely "part of the repudiated world, the not-me" (Winnicott 55). While the latter would be "outside magical control," one cannot play by merely thinking or wishing: "Playing is doing" (55). Rather than locating the area of play in the merely psychical or in the merely external, Winnicott conceives of it as a "potential space between the baby and the mother." This potential space is con- 
trolled by the mother-figure who provides the baby with an experience of omnipotence (63). In localizing play, Winnicott makes out two sequential relationships: a) "baby and object are merged with one another," and b) "the object is repudiated, re-accepted, and perceived objectively." If the mother-figure can perform this play

in a "to and fro" between being that which the baby has a capacity to find and (alternatively) being herself waiting to be found [then] the baby begins to enjoy experiences based on a "marriage" of the omnipotence of the intrapsychic processes with the baby's control of the actual. (63)

It is thus the experience of having and not-having while imagining oneself entirely in control when the having happens:

Into this play area, the child gathers objects or phenomena from external reality to and uses these in the service of some sample derived from an inner or personal reality. Without hallucinating, the child puts out a sample of dream potential and lives with this sample in a chosen setting of fragments from external reality. (69)

The child experiences having control over these transitional objects, which belong to both the internal and the external sphere.

In theater generally, and in improv in particular, performers are modally forced to treat and read their scene partners as fellow improvising Human beings and - simultaneously - as fictional characters to whom their own fictional characters react. Playing, then, is an apt conceptualization and definition for what happens on the improv stage, but for reasons other than usually asserted. It has much more to do with the players imagining they have magical control over the world in regard to themselves, that is, their own integral imagination of a world that provides complete integrity: "In playing, the child manipulates external phenomena in the service of the dream and invests chosen external phenomena with dream meaning and feeling" (69). Improvisers are always interpreting what is happening around them to their own view of what has been happening; they are always reading whatever is happening as "me-extensions" (135). ${ }^{1}$ It is thus significant if the adult improviser, in bios/mythoi hybridity, has been preprogrammed to intuitively regard a certain racialized kind of fungible Black

1 As Winnicott goes on to tell us: "From the beginning, the baby has maximally intense experiences in the potential space between the subjective object and the object objectively perceived, between me-extensions and the not-me. This potential space is at the interplay between there being nothing but me and there being objects and phenomena outside omnipotent control" (135). 
body as a me-extension, in addition to this being a central mode of play. Winnicott links this to Erikson's work on identity-formation, and we can immediately see how the notions of play and subject-making as mobilized in improv discourse relate to anti-Black abjection, to establishing the subject's own sense of coherence within the logic put forward by Afro-pessimist thought.

\section{Transitional Blackness}

As I hinted above, playing as adults is not innocent. The anti-Black matrix provides the discursive and libidinal ground for the desired subject-aeffect, which is predetermined in the anti-Black discursive DNA. Blackness provides the frame, the mode, and the material for this experience. This has much more to do with devouring, owning, controlling, and possessing than with equality. In their continual, fungible ownability, Blackness and every signifier carrying its burden are ideal transitional objects for white subjects-in-the-making. White people's play is the culturally specific performance of personal freedom based on the destruction of (Black) transitional phenomena. Even though Winnicott permits us to expand his play theory to a cultural level, it may seem that we are entering dubious epistemological terrain. ${ }^{2}$ Like most psychoanalytic theorists, Winnicott is bound to his universalizing gesture, suggesting his theory is valid for all humankind. We can only specify his model by positioning the brackets of a critical approach to Humanism in the first place - as Broeck did with Kristeva's notion of abjection. We must recognize that Winnicott is himself subject to the white ignorance that never ceases to generate fantasies of all-encompassing universalisms. Without challenging the mechanisms described in his play theory, we must specify that he lives in the "racial fantasyland" (Mills, Contract 18) of white people, which, by definition, makes itself invisible to its inhabitants. He is speaking from within this fantasy land, and whatever his universalist arguments may gesture toward, he can at best speak about this fantasy world and never beyond. His findings are not wrong; they are culturally specific.

While Winnicott mostly speaks of the (biologized) "mother" or refers to the breast as "part of the mother," on one of two occasions he allows for a less-gendered "mother-figure," leaving it unclear who or what can take the place of the biological mother (55). I suggest that this mother-figure be transumed by the matrix - Latin for “womb” - of white Western modernity, as elaborated by Wynter.

2 Winnicott writes: "There is a direct development from transitional phenomena to playing, and from playing to shared playing, and from this to cultural experiences" (69). 
For Winnicott, the mother is responsible for the child's self-experience in the area of play, as defined above: "Playing implies trust, and belongs to the potential space between (what was at first) baby and mother-figure, with the baby in a state of near-absolute dependence, and the mother-figure's adaptive function taken for granted by the baby" (69). Whereas a mother can be "not good enough" - she may fail to provide a background against which a child develops trust in itself in the face of disillusionment (recognizing an external reality) as they transition from one developmental stage to another - this is not the case for the modern matrix of the Western subject. The modern matrix can be said to provide the same trusting space for white play and creativity, better even than the original mother could. We can legitimize the transumption of the mother-figure to mother-culture by recognizing with Winnicott that "this language involving 'the breast' is jargon. The whole area of development and management is involved, in which adaptation is related to dependence" (124). To the very degree to which the modern matrix becomes a culturally specific mother/breast-figure, providing the white subject with magical feelings of omnipotence and ownership over the external world, Blackness becomes the transitional signifier for adults not by choice but by logical necessity (involving both cultural objects and phenomena like songs, ways of behaving, gestures, micro-elements... anything that can carry the meaning of Blackness).

Objects, bodies, and phenomena that signify Blackness fulfill for the white subject all the functions of transitional objects. Most prominently, Blackness triggers the white subject's need (and capacity) for ongoing destruction. To address the linkage between play and destruction, we need to follow Winnicott's differentiation between object-relating and object-usage:

In object-relating the subject allows certain alterations in the self to take place, of a kind that has caused us to invent the term "cathexis." The object has become meaningful. Projection mechanisms and identifications have been operating and the subject is depleted to the extent that something of the subject is to be found in the object. (118)

If an object is used, the user must understand the object additionally as part of an external, shared reality; it is not just "a bundle of projections." Accordingly, "relating can be described in terms of the individual subject" (as a solipsist procedure), while "usage cannot be described except in terms of acceptance of the object's independent existence, its property of having been there all the time" (118). Object-relating and object-usage are by no means contradictory. They denote two different stages in emotional development. Of two infants feeding at the breast, one may be feeding on the self "since the breast and the baby have not yet become (for the baby) separate phenomena," while the other 
may be feeding on an "other-than-me source, or an object that can be given cavalier treatment” (Winnicott 118-19). Object-relating and object-usage are thus the two stages in between which playing takes place, and which are animated simultaneously by play. Playing is the activity of "feeding from the self" and "feeding from an other-than-me source." The same can be said about the solipsist encounter or engagement of white subjects with bodies, objects, or phenomena racialized as Black: it is motivated by and feeds back into the self, but it is dependent on the external existence of sign-vehicles or phenomena. We can read continual anti-Black abjection as play when we think along with Winnicott's argument of the destruction of the object. He suggests that the transition "from relating to usage means that the subject destroys the object." In recognizing the object as an "entity in its own right," the subject was present in object-relating with its cathectic qualities, in perceiving it as an external phenomenon rather than conceiving it as a subjective object. This originary, affective understanding of the transitional object is lost, and the object as was is destroyed. Accordingly, the idea of "using an object" is only meaningful in the area of simultaneity as considered here (120). ${ }^{3}$

However, the heuristic differentiation Winnicott subsequently presents is both horrifyingly intriguing and easy to misunderstand:

[T] here is an intermediate position. [After] the "subject relates to object" comes "subject destroys object" (as it becomes external); and then may come "object survives destruction by the subject." [...] A new feature thus arrives in the theory of object-relating. The subject says to the object: "I destroyed you," and the object is there to receive the communication. From now on the subject says "Hullo object!" "I destroyed you." "I love you." "You have value for me because of your survival of my destruction of you." "While I am loving you I am all the time destroying you in (unconscious) fantasy." Here fantasy begins for the individual. The subject can now use the object that has survived. (121)

This is an adequate description of the dynamic back-and-forth of white solipsist anti-Black abjection. The object here is not an object qua relationality. Quite the contrary, it functions as a transitional object open to and available for the subject's fantasies of omnipotence. Like Blackness, the transitional object is characterized by its destructibility and expendability, and becomes real/external qua its destruction. In its effect, it is fungible, like sign-vehicles of Blackness. Transitional Blackness thus provides the white subject-body with a means to meet a

3 In this argument, we can open up the libidinal grounds of what has been termed white fragility. Somewhere, we white people know (or fear) that Black people are human beings like us - with autonomous wills, minds of their own. If we accept that, we are thrown into the vertigo of none-subjectivity; anti-Black abjection as play throws us in and gets us out all at once. 
need for omnipotent, magical control, for the integrity and invigoration of the self. In infant play, the externalization originates in the feeling of unity with the mother, of utter bliss and substantial integrity. In adult play, this externalization describes the anti-Black abjective procedure, an affective motion sociogenically inscribed into the subject-bodies of the modern West. Several points in Winnicott's description of the use of an object reverberate powerfully with the abjective modes of fear and desire: the invigoration of the white self, the nonchalant productiveness of destruction, and the idea of Blackness-as-transitional object or transitional Blackness. He writes:

The object is always being destroyed. This destruction becomes the unconscious backcloth for love of a real object; that is, an object outside the area of the subject's omnipotent control. Study of this problem involves a statement of the positive value of destructiveness. This destructiveness, plus the object's survival of the destruction, places the object outside the area of objects set up by the subject's projective mechanisms. In this way a world of shared reality is created which the subject can use and which can feed back other-than-me substance in the subject. $(126-27)$

When Winnicott mobilizes destruction, he thinks of "the subject creating the object in the sense of finding externality itself, and it has to be added that this experience depends on the object's capacity to survive." He goes on to say - and this is central - that "survive', in this context, means 'not retaliate"” (120). Even though externalized, the object will not leave the baby/subject. While it represents the baby/subject's lack of omnipotence due to its actual, external, and separate existence, in play it always remains open for abuse. It thus performs that lack and the presence of both lack and omnipotence.

As a floating signifier, Blackness will also always survive without retaliation, even if white play actually destroys a Black-racialized body or object. Blackness will always be there to provide fungible matter: an individual object may be destroyed, but this does not damage transitional Blackness as the structurally abjected sphere, because any sign, mode, or gesture meaning Blackness may serve the abjective function that I identify as the same aeffect created by play. And while the white subject needs Blackness to become an external, manipulatable object or phenomenon, that object's or phenomenon's very externality is a threat to the white subject. The white subject is thus both threatened by and dependent on Blackness as a transitional object when play turns into culturally specific abjection. Given this reliance on transitional Blackness, Schiller ultimately (and unexpectedly) turns out to be correct when he states that "man only plays when in the full meaning of the word he is a man, and he is only completely a man when he plays" (80). Because he destroys. Because he abjects. Consider also the uncanny summary Winnicott gives of the special qualities in the relationship be- 
tween the individual and the transitional object-phenomenon, which reverberates loudly with the functions that Blackness serves for the white modern self: "the infant [white subject] assumes rights over the object, and we agree to this assumption. Nevertheless, some abrogation of omnipotence is a feature from the start" (7). Here are the property claims made by a white subject over Black bodies, materials, and cultural productions from the start. While we white subjects agree to this structurally, whiteness has an inbuilt fragility: should we recognize Black-racialized bodies as existent within relationality, that would equate with the subject's abrogation per Winnicott. Further, Winnicott states that "the object is affectionately cuddled as well as excitedly loved and mutilated," and "must survive instinctual loving, and also hating and [...] pure aggression" (7). This involves simultaneous love and hate, fear and desire, destruction and dependence, and the lack of capacity to retaliate that we can observe in white mobilizations of Blackness. The transitional object or phenomenon "must never change, unless it is changed by the infant." This lack of autonomous will on the part of an otherwise externalized transitional Black phenomenon enables the subject to experience the subject-aeffect of omnipotent power over the world and its own being. Moreover, the transitional object "comes from without from our point of view, but not so from the point of view of the baby. Neither does it come from within; it is not a hallucination” (7).

Its fate is to be gradually allowed to be decathected, so that in the course of the years it becomes not so much forgotten as relegated to limbo. By this I mean that in health the transitional object does not "go inside" nor does the feeling about it necessarily undergo repression. It is not forgotten and not mourned. It loses meaning, and this is because the transitional phenomena have become diffused, have become spread out over the whole intermediate territory between "inner psychic reality" and [...] the whole cultural field. (7)

We are looking at an external object or phenomenon as the source for the internal, biopsychical sensation of the subject-aeffect, an external stimulus for a solipsist procedure.

When Winnicott claims that "playing is essentially satisfying," which is "true even when it leads to a high degree of anxiety" (70), I would add that in its specific anti-Black improv variant, adult play is grounded in excitement and the (omnipotent) control of that excitement. There is an imagined insecurity in not knowing what will happen next and additional insecurity within the white subject-body in the potential (real or imagined) encounter with Blackness. However, I want to suggest that this anxiety is enjoyable in either case, much like Kristeva's horror: "[T]he void upon which rests the play and with the signifier and primary processes [and] the arbitrariness of that play are the truest equivalents of fear" (Kristeva 37). By way of analogy, we can read this along with what 
happens on the improv stage. We might say that at the beginning, improvisers throw themselves into a situation in which Blackness may potentially denote symbolic life, including the autonomous agency that comes with it, and then playfully abject themselves back into order. After the experience of abjective play, the white subject "comes out" cleansed and rejuvenated. For Winnicott, this is the defining feature of playing:

Playing is inherently exciting and precarious. This characteristic derives not from instinctual arousal but from the precariousness that belongs to the interplay in the child's mind of that which is subjective (near-hallucination) and that which is objectively perceived (actual, or shared reality). (70)

Keeping in mind the destructive and devouring aspects that define transitional Blackness, this offers a remarkably succinct description of white solipsist encounters with Blackness, whether on or off stage. Improvisers may seek precisely this anxiety of the unknown when pursuing their craft - the secure but playful look into the abyss of one's own imagined subjectivity, while knowing that ultimately the white subject will always be in control, that our modern mother-matrix will always be there. Can we see this solipsistic violence against transitional Blackness actually play out in an improv scene? Can we translate this violently playful simultaneity of externalizing an internal experience into a solipsist moment, into a theatrical situation of staged improv where Black improvisers are dehumanized beyond the rhetorical scope of misrepresentation and stereotypification? What happens if a player transitionally racialized as Black performs retaliation? Approaching these questions, I will now consider the phrase "treating somebody as a prop" and test its literal meaning by discussing theorizations of property and property rights.

\subsection{Improvising property}

\section{Meaningful matter: semiotizing the racial improv prop}

"I will never play with anybody who will use me as a prop to get a joke off," states Aasia Bullock in personal conversation. The improv prop as a concept is borrowed from the world of scripted theater. In improvised theater, which is celebrated for not needing props, "making somebody a prop" means exercising control over one's scene partner, using them to serve and express one's own idea. The body-as-prop exists only insofar as it serves the ideas of the propertizer. It is disabled or discouraged from introducing its own ideas to the scene. Rather 
than defining the scene partner (or entering the scene oneself) as a tree, a telephone, or a lamppost, "making somebody" a prop denotes a reduction of their creative options, rendering them intellectually inflexible and foreclosing the Human potential they might otherwise display. It is thus a dehumanization that attempts to constrain the scene partner to an unchangeable function in service of the propertizer's scene or story. The prop is treated as fixed bodily matter without even the capacity to control that matter's signification beyond its matterness. In improvisation, then, such propertization can be read as the attempt to strip the scene partner of the autonomy so essential to democratic free play. Yet while making somebody a prop undermines the egalitarian ideals of improv, it becomes a key characteristic in play, as defined by Winnicott: as an external phenomenon, the scene partner is manipulated in the service of the manipulator's fantasies and dreams. When treated as a prop, the scene partner serves merely as an external stimulus for the realization of the truly improvising white agent doing the propertizing. More than just a cliché, the concept of the prop is highly instructive for three central reasons:

1. It is closely intertwined with intuition as the ground for spontaneous decision-making. It demonstrates individual and collective affective structures of improvisers: a Black-racialized body on the improv stage is always already somatically marked by anti-Black abjective sensations and will be reacted to on this libidinal ground.

2. It is not a metaphor. The racialized treatment of scene partners as props is not about representing stereotypes or the fictionalized reenactment of enslavement but describes the actual performance of the enslavist, dehumanizing, propertizing regime that gives rise to the contemporary white subject celebrated in improv.

3. It functions on the aesthetic level of theater semiotics: the propertized improviser (an oxymoron) can be moved, shifted, and used for the propertizing white subject's own purposes. This happens on the abjective grounds of (necessarily) anti-Black subjectification and facilitates the communication between a white, Human, improvising cognizer and its Human audience, the referent-we of white improv, without the propertized being itself part of this Human sphere of sociability.

Despite these compelling reasons, the prop in theater has received remarkably little attention in the academy. Scholarly writing on props usually consists of instructions for prop makers, and theater semiotics is only tangentially concerned with props. One exception is Andrew Sofer's The Stage Life of Props. As a theater practitioner himself, he offers a multidisciplinary approach in exploring what a prop is, how it works, and what it does on the theatrical stage. Most importantly, 
he considers how an object becomes a prop. Following Sofer, the prop exists at the nexus of materiality and sensual perception on the one hand, and its meanings and signifying functions on the other. Thus it is located right in the center of theater semiotics and instigates debate. Sofer quotes Freddie Rokem as a strong critic of the purely linguistic perspective on the prop. Rokem argues that "the linguistic approach is not able to cope with the fact that even if the object becomes a sign, it never loses contact with its materiality as embodied by that particular object which is present on stage" (qtd. in Sofer 14). Further, "the palates of our mind are stimulated primarily by the chair as a material object and not only as some abstract linguistic food for thought" (15). Sofer specifies the standard OED definition of the prop by defining it as "a discrete, material, inanimate object that is visibly manipulated by an actor in the course of performance." Consequently, being a prop is not an inherent quality of an object, but a quality that an object attains by "Human touch." As Sofer goes on: "It follows that a stage object must be 'triggered' by an actor in order to become a prop," otherwise it will remain decor. Further, "irrespective of its signifying function(s), a prop is something an object becomes, rather than something an object is" (11-12). Sofer draws this description from Jirji Veltruský's article "Man and Object in the Theater." The Prague School semiotician suggests "a fluid continuum between subjects and objects on stage" (qtd. in Sofer 9), so that human bodies can indeed be read and treated as props, granted that they lack an action-force on their own, such as those representing death:

To use Veltruský's own example, a stage dagger might move from being a passive emblem of the wearer's status to participating in the action as an instrument of murder, and thence a final independent association with the concept "murder." Conversely, when the actor's "action force" is reduced to zero, the actor takes on the status of a mere prop (e.g., a spear carrier or corpse). Actor and prop are dynamic sign-vehicles that move up and down the subject-object continuum as they acquire and shed action force in the course of a given performance. (Sofer 9)

For Sofer, the actor and the prop are two extremes on a continuum, which allows the actor to manipulate the prop (Humanoid or other) to their own ends, while the reverse is not possible. Even though for Sofer (and post-Prague school theater semioticians), the idea of an "“action force' remains murky" (9), in the present context it is quite revealing when read along with improv's Humanist ideals. If we conceive of "action force" as an almost dramaturgical notion, then we can translate it directly into Bergson's idea of an élan vital, a life force, which an audience watches improvisers display and showcase on stage. Such life-force, in improv or elsewhere, corresponds to how whiteness "monumentalizes its subjec- 
tive capacity, its lush cartography, in direct proportion to the wasteland of Black incapacity" (Wilderson, Red 45).

It follows that the theatrical prop is not a phenomenological concept but a functional one, which can be easily related to the equally functional concept of Blackness, that is, to the Black-racialized body as a "will-less actant" in Saidiya Hartman's term (62). The Black body, "seen as paradigmatically a body" (Mills, Contract 51), is located in the base, earthy, non-homogenous nadir of the earth's matter rather than in the lofty realms of spirits and mind. Like the prop, the Black body is characterized by the perceived foregrounding of its materiality. Without the discursive capacity to harbor a mind, spiritual or rational, it lacks the potentiality of a white subject's action-force. The Black-racialized body on the improv stage is not treated as a prop; it is the paradigmatic prop for US American entertainment. This analogy, identity even, applies equally to the human body-as-corpse, symbolizing social and material death. Remembering that a prop "never loses contact with its materiality," one technique of making somebody a prop is to do just that: foreground that person's actual body by calling out Blackness. Consider this anecdote from Kimberly Michelle Vaughn:

I did a jam at Second City recently. It was with teachers and new students. We did a scene, and it was in German, we were all doing German accents and whatever. I was the main person, and apparently, they were scientists. Then they said: “Ok, we're going to strip off your skin, and put a white skin on.” These are teachers. White teachers, telling me they were gonna put someone's white skin on me. You could already feel the audience gasping. I was like, "You are not going to strip off my skin as a white person." And the white doctor scientist was like, "No, we're going to strip off your skin because we want you to be no longer insecure. We want you to blend in with society." This is going on on-stage. And then I was going on: "No. It must be so hard to be white, with all that privilege." And one of the other scientists went on: "Oh, it's so hard being vite, because ze guilt, ze guilt..." And then we get a blackout and a proper reaction of laughter. At the same time, I was so mad and wanted to cuss out everyone on stage. But I loved how I stood my ground, regardless of whatever was going on. I was just very uncomfortable. I couldn't believe that teachers at this famous place, Second City, still didn’t know how to act in a scene like that. It blew me. I don't think they understood what was going on. (personal conversation)

In this account, the intuitive standard of treating a Black-racialized scene partner exclusively in terms of Black flesh speaks to Wynter's elaboration of the antiBlack matrix, in which Blackness takes the place of pure matter, of the non-moving earth as opposed to the higher (scientific!) reasoning available to white people. On the level of non-egalitarian play, this content was performed over the body of the Black-racialized improviser, whose "no" was white-ignored because its consequences would be unfathomable for the white majority on the stage. In Sofer's words, what happened here for the white referent-we was the perfor- 
mance of a prop "gone awry" (24). He calls this "an instance of autonomy, or pseudoautonomy" on the part of the prop, in the sense that it no longer works according to the set realities of the scene, the rules of the game. It was an autonomous act that was immediately derailed and abjected. The Black improvising body saying "no" was abjected, and its discursive impossibility reinstalled in much the same way that Adorno discusses his "jazz subject," treating it like the (impossible) "rebellious [n-word]" (Judy 225). ${ }^{4}$

The maintenance of a Black scene partner's status as a prop is invaluable for the white player who lives on his characteristic of being a Human prop-mover. The Black improv performer - a discursive paradox - does not hold the capacity to reverse-propertize a white scene partner. In Scenes of Subjection, Hartman writes:

After all, the rights of the self-possessed individual and the set of property relations that define liberty depend upon, if not require, the black as will-less actant and sublime object. If white independence, freedom, and equality were purchased with slave labor, then what possibilities or opportunities exist for the black captive vessel of white ideality? (62)

In relating the improv scene to real-world behavior, Kimberly Michelle Vaughn displays an optimism of the will and a pessimism of the mind when it comes to collectively unlearn the instinct of anti-Black propertization:

It's hard when someone keeps making you a prop. Even in situations other than improv. Like in your friends group. All white people, but you need that one black person at the party, right? We're always going to be a prop. But we can't make ourselves a prop anymore. And that's why I think when someone calls us out, we definitely have to make them look stupid for making us that. But it's so annoying that we have to do that. (personal conversation)

\section{Judy writes:}

A bad [n-word] [...] is an oxymoron: rebellious property. In rebellion, the bad [n-word] exhibits an autonomous will, which a [n-word] as commodity-thing is not allowed to exhibit. There is little more dangerous than a willful thing, through the exhibition of autonomous will, the bad [n-word] marks the limits of the law of allowance by transgressing it [...] The bad [n-word] indicates individual sovereignty, which is to say he is self-possessed. What is at stake here is not the obvious problem of the bad [n-word] embodying the Enlightenment subject (i.e., exhibiting the characteristics of the autonomous subject who is the cornerstone of both civil society and the state). The real threat of the bad [n-word] is in exhibiting the groundlessness of the sovereign individual. Being a [n-word] appearing as a human, the bad [n-word] indicates the identification of human with thing, that the human can only be among things, cannot be beyond or abstracted from things. The bad [n-word] is a humancum-thing. (225) 


\section{Necessary things}

That people can be treated as props illuminates how the universalist ethics of free expression and egalitarian play are continuously undermined on a comedy stage. In improv, we have individual Humans on the stage, and these Human subjects act freely. Such personhood is historically bound to propertization in the first place, as legal scholar Margaret Jane Radin argues:

The premise underlying the personhood perspective is that to achieve proper self-development - to be a person - an individual needs some control over resources in the external environment. The necessary assurance of control takes the form of property rights. $(957)^{5}$

Being a person in the first place means having the capacity to structure and control an external reality rather than being controlled and structured by it. Since a subject requires property to exert that control, property must be viewed within a context "that focuses on personal embodiment or self-constitution in terms of ‘things”” (958). Radin explains:

If autonomy is understood as abstract rationality and responsibility, it fails to convey this sense of connection with the external world. Neither does liberty, if understood in the bare sense of freedom from interference by others with autonomous choices regarding control of one’s external environment. (960)

The notion of (and experience as) a self is thus "intimately bound up with things in the external world" $(960-61)$. This is highly relevant to the practice of improvisation, where the modern self is showcased as the central attraction on the stage and will thus perform in the mode of manipulative control more often than not. It follows that the abjective moves in the examples I have presented are not glitches or extremes but rather necessities for this white autonomy to exist, performed from the standard default of anti-Black abjection. The German term for prop, "Requisite," (like the English adjective "requisite") comes from the Latin

5 I invite the reader to read the "need for control over resources in the external environment" as a prerequisite for personhood and self-development throughout the entire libidinal register laid out and elaborated upon in the previous chapters, and grounded in Freud's assertion that we draw on externality to satisfy internality. I understand this legal dimension is "on top," or at least "along with" these. Actual ownership must then be understood to provide an abjective subject-aeffect. This aspect is, of course, not presented accidentally at this point of the argument, but must be understood in the primary ownership of those enslaved bodies, Others to Human subjectivity that could hold no ownership and were, consequently, bound to be owned themselves. 
requisitum, which roughly means "necessary thing." In terms of improv, this is especially telling; the person who is abjected and owned by the owner-subject is also existentially necessary for this subject, that is, for the freely improvising actor-agent on the stage. Without this capacity to own, the actor would have nothing to play with (in Winnicott's sense). We might go as far as to say that there is no improvising subject beyond the precarious prop established early in the scene. If an improviser feels they are in a state of uncultured nature and unbridled opportunity (as is the - alleged - tabula rasa of the beginning improv scene, not unlike Robinson Crusoe stranded on the island), they will also feel the need to organize it. This is their task as a modern white subject: to establish a property regime on the grounds of Black-racialized abjected bodies.

\section{Property rights and their communication}

Contemporary property theory does not conceive of property as something inherent in objects independent of the symbolic exchanges within which that property is traded, and which gives rise to it in the first place. Rather, property is understood in its communicational function - very much like Sofer's functional theory of the theatrical prop. In the early twentieth century, and in the wake of the Marxist denaturalization of property, jurist Wesley Newcomb Hohfeld completely dismissed the idea of property-as-thing and, as Carol M. Rose notes in Property And Persuasion, "pointed out that larger entitlements could be analyzed as a series of claims and obligations of varying sorts among persons" (1). Before looking at the communicational dynamics of propertization, we must consider who qualifies for these "larger entitlements" based on the racialized origins of the US property regime itself.

In "Whiteness as Property," legal scholar Cheryl Harris explains how whiteness as such can be framed structurally as a fundamental property required for modern subjective capacity, engaging with the "valorization of whiteness as treasured property in a society structured on racial caste" (1713). She analyzes "the evolution of whiteness from color to race to status to property as a progression historically rooted in white supremacy," based on the observation that "whiteness and property share a common premise - a conceptual nucleus of a right to exclude" (1714). Modern US ownership has thus always been raced:

[S]lavery as a system of property facilitated the merger of white identity and property. Because the system of slavery was contingent on and conflated with racial identity, it became crucial to be "white," to be identified as white, to have the property of being white. Whiteness was the characteristic, the attribute, the property of free human beings. (1721) 
Harris makes it clear that property must be understood first as a right and second as an object or a thing; it is "characterized as metaphysical, not physical" (1725). She argues that the practice of possession, "the act necessary to lay the basis for rights in property [...] was defined to include only the cultural practices of whites" (1721). Whiteness as a property right ensured that those identified as white could never become somebody else's property, while those racialized as Black could. In a system that enshrines white personhood with freedom-as-unownability, ownership becomes a praxis of self-actualization - always with the enslaved absolutized Human Others in unmediated view, denying them this freedom.

The modern practice of possessing and exercising this racialized and exclusively white right is founded on what Radin calls "property's quintessential moment of chutzpah: the act of establishing individual property for one's self simply by taking something out of the great commons of unowned resources" (9). Rose names two central ways to take possession of property or resources: "(1) notice to the world through a clear act and (2) to reward useful labor" (13). Both are based on traditional axioms of property theory: a Lockean believe that property comes about by mingling one's labor with the thing, and what Rose calls "consent theories," which rest on the assumption that "the original owner got title through the consent of the rest of humanity" (11). Giving notice to the world invariably involves some kind of speech act because it happens in the social mode of communication. According to Rose, this "clear-act principle [...] defines acts of possession as some kind of statement. As Blackstone said, the acts must be a declaration of one's intent to appropriate" (13). In terms of land, say, this means that whoever lays claim to a plot of land first communicates this claim to the rest of the world, which then gives consent to this firstness by allowing the earliest agent to own that particular plot. Thus, irrespective of ontology, property must be framed as relational: not between the owner and the owned, but between the communicating agency (or agencies) that regulates the property regime of who owns what. Property is the material for relationality. This relationality comes about via communicative speech acts of negotiation:

Possession now begins to look even more like something that requires a kind of communication, and the original claim to property looks like a kind of speech, with the audience composed of all others who might be interested in claiming the object in question. Moreover, some venerable statutory law requires the acquirer to keep on speaking, lest she lose title through the odd but fascinating doctrine of adverse possession. ${ }^{6}$ (Rose 14)

6 Rose continues: "The doctrine of adverse possession thus transfers property from the title owner to another who is essentially a trespasser, if the trespasser's presence is open to everyone 
To return to improv practice, making somebody a prop involves reading an abject body as an "unowned resource," that is, one that is not in possession of itself (otherwise we would not feel entitled to do so in the first place). Performatively, this procedure involves (speech) acts of laying claim, and these acts request and enable cultural consent. In view of Black-racialized improv props, the claimants can safely count on the intelligibility of Blackness as a vast "unowned resource," descriptively designed especially for the procedure of white modern subject-making and sociability. In the scene related by Vaughn, one of the white improvisers did not respect (ascribe) autonomy to her as an improviser but foreclosed her from the Human fold by drawing on her Blackness as an unowned resource. Vaughn was not given autonomy over (the meaning of) her body. Even though she rejected the skin-change offer, the white, acquiring improvisers in the scene "kept on talking" to ensure continual collective white claimantship over the Black-racialized body. We need to recognize how the white improvisers as scientists felt entitled to make racialized use of Vaughn's presence on the stage. Reduced to Blackness, the fungibility of Vaughn's racialized body was called out: the scene could have been the same with any other Black-racialized performer. Vaughn provided matter and meaning to the scene. Even though she did all she could to preserve a (pseudo?)autonomy, she was not heard when she spoke. Her performance of autonomy was unintelligible for her white scene partners and corresponded to the paradox of the "rebellious [n-word]" (Judy 225).

and lasts continuously for a given period of time, and do long as the title owner takes no action to get rid of him during that time" (15). 